\title{
DIPTEREN I
}

VoN

\section{DR. J. C. H. DE MEIJERE iN HILVERSUM.}

Mit Tafel I. 
PRAEDA ITINERIS

a L. F. de Beaufort in Archipelago indico facti

annis 1909-1910.

VI.

\title{
Dipteren I
}

VON

\author{
Dr. J. C. H. DE MEIJERE \\ IN HILVERSUM.
}

Mit Tafel I.

Während Ihres Aufenthaltes auf Waigeu und der benachbarten kleinen Insel Saonek, und auf Ceram hat Frau C. F. DE BEAufort sich in sehr dankenswerter Weise mit dem Sammlen von Dipteren beschäftigt. Sie brachte eine ganze Anzahl von 'denselben zusammen, deren Bearbeitung ich sowohl wegen der in dipterologischer Hinsicht noch wenig untersuchten Fundorte, wie wegen des, recht gaten Conservationszustandes (alles war an Ort.und Stelle gespiesst) gerne unternahm.

Die Anthomyinen habe ich Herrn Prof. Stein in Treptow a/R zur Bearbeitung zusenden. dürfen; auch die übrigen Calyptraten bleiben einstweilen unbeachtet. Die Sarcophaga-Arten sind zur Zeit in den Händen des Dr. Villenedve, der hoffentlich auch in der Lage sein wird das weitere Material dieser Gruppe zu studieren.

Ueber einige erbeuteten Tabanus-Arten berichtet Miss RrCakdo in dem nächstfolgenden Aufsatz:

Unter den von mir untersuchten Tieren findet sich, wie zu erwarten, eine Reihe von neuen Arten, ausserdem mehrere, welche mir entweder aus Java, oder durch die Neu-GuineaExpeditionen bekannt wurden. Es findet sich auf allen den besuchten Inseln eine Mischfauna orientalischer und papuanischer Arten. Ceram zeigt relativ eine grössere Anzahl Javanischer Formen wie Waigeu; indessen lassen sich wegen der noch ungenügenden Kenntniss der Dipteren dieser ganzen Region weitere allgemeine Schlüsse zur Zeit nicht ziehen. Als Baustein für spätere umfassendere Betrachtungen möge die kleine Arbeit ihren Wert zeigen.

\section{SCIARIDAE.}

\section{Sciara Meig.}

Sciara turrita n. sp: (Fig. 1, 2).

Ceram, Februar, 1 ㅇ.

․ Fühler schwarzbraun, von halber Körperlänge. Kopf (Fig. 1) mattschwarz, Stirne in der Mitte des Scheitels mit einem cylindrischen Zapfen, welcher ungefähr so lang ist wie die mittleren Fühlerglieder; Taster schwarz.

Thorax schwarz, wenig glänzend, fast nackt. Brustseiten, Hinterleib und Beine schwarzbraun, der Hinterleib kurz schwarz behaart. Flügel (Fig. 2) schwärzlich, die Ausmündung der $1^{\text {ten }}$ Längsader ungefähr über der Wurzel der Gabel. Schwinger schwarz.

Körperlänge $4,5 \mathrm{~mm}$; Flügellänge $4,5 \mathrm{~mm}$. 


\title{
MYCETOPHILIDAE.
}

\author{
Leia Meig.
}

Ceram, Februar.

Leia nigra n. sp. (Fig. 3).

Stirne mattgrau, wejsslich behaart, nur 2 deutliche Ocellen vorhanden. Fühler cylindrisch, schwarzbraun, bedeutend länger als der Thorax. Untergesicht und Taster gelblich.

Thorax und Hinterleib ganz schwarz, die Behaarung des Thorax schwarz, die anliegende Behaarung des Abdomens gelblich schimmernd. Beine gelb, die Wurzelhälfte der Hinterhüften und die Endhälfte der Hinterschenkel schwarz, auch die Spitze der Mittelschenkel, die Unterseite der hinteren Schenkel, die hinteren Schienen und alle Tarsen verdunkelt. Vorderschiene solang wie der Metatarsus, innen an der Spitze mit einem gelben Sporn; hintere Schienen aussen mit 2 Reihen von schwarzen Dornen, an der Spitze mit 2 gelben Enddornen, Mittelschienen ausserdem mit einem langen schwarzen Dorn an der Innenseite, etwas vor der Mitte. Flügel (Fig. 3) an Vorderrand und Spitzenhälfte merklich gebräunt; von der oberen Gabel beide Zinken vollständig, von der unteren ist die obere Zinke an der Wurzel abgebrochen. Schwinger weiss.

Körper- und Flügellänge 2,5 mm.

In der Gattung Leia sind beide Gabelzellen an der Wurzel unvollständig; die vorliegende Art weicht also durch die vollständige obere Gabel vom Gattungscharacter ab.

\section{CULICIDAE.}

Toxorhynchites Theob.

Toxorhynchites amboinensis Dol.

Ceram, Februar, $2 \sigma^{7}$.

Die Art zeichnet sich durch die einfarbig dunkelblauen Haarbüschel an den Seiten der Hinterleibsspitze aus. Der weisse Ring an den Hintertarsen, dessen genaue Stellung Tnmobald im $5^{\text {ten }}$ Bande seines "Monograph of the Culicidae" p. $9^{7}$ noch unentschieden lässt, nimmt die Wurzelhälfte des Metatarsus ein, die Oberseite ist auch hier jedoch ganz schwarz, der Ring also nicht geschlossen. Im übrigen sind die Beine des $0^{7}$ ganz schwarz.

Ceram, Februar, 1 ㅇ.

$$
\text { T. subulifer Dol. }
$$

Dieses $q$ ist leider nicht vollständig erhalten, es fehlen die beiden hinteren Beinpaare. Unterschiede mit dem 우 von $T$. immisericors Walk. sind folgende: Bei letzterem besteht der vordere Teil der seitlichen Haarbüschel aus goldgelben Haaren, während bei subulifer \& diese Büschel fast ganz schwarz sind, nur finden sich vorn, am Ende des 6 ten Ringes, einige weisse Haare; das letzte Segment ist gelbbehaart.

Während immisericors $\$$ gelbbeschuppte Seitenflecken besitzt, finden sich bei subuitifer $q$ weisse Flecken. Bei immisericors $O$ ist das $1^{\text {te }}$ Tarsalglied und die Wurzelhälfte des $2^{\text {ten }}$ an den Vorderbeinen ringsum weiss, bei subulifer $q$ ist das Spitzendrittel des $2^{\text {ten }}$ Gliedes oben breit schwarz beschuppt, nur die Unterseite ist ganz weiss; das $2^{\text {te }}$ Glied ist oben am Spitzenviertel schwarz, bei immisericors nimmt die schwarze Farbe hier fast die Spitzenhälfte ein.

Wenn wir beachten, dass zwischen amboinensis $\sigma^{7}$ und subulifer o ähnliche sexuelle Differenzen in der Beinfarbe vorherrschen wie bei den 2 Geschlechtern von T. immisericors, so drängt sich die Ansicht auf, dass subulifer das $q$ zu amboinensis ist. Die Ansicht wird dadurch unterstützt, dass eins der obigen Männchen und das $ᄋ$ an einem und demselben Tage erbeutet wurden. Doleschall besass von subulifer lediglich 2 Weibchen; dass er von seinem amboinensis beide Geschlechter erkannt hat, geht aus seiner Beschreibung nicht deutlich hervor; wohl erwähnt er im besonderen das $\sigma^{x}$. Ich möchte glauben, dass seine Beschreibung nur auf dieses Bezug hat. 
Stegomyia Theob.

Stegomyia scutellaris Walk.

Ceram, Februar.

Desvoidya Blanch.

Desvoidya obturbans Walk.

Ceram, Februar; Waigeu, Dezember.

\section{LIMBOBIIUA E.}

Atarba 0. S.

Saonek, Dezember, 1 ㅇ․

Atarba sp.

Das Exemplar sieht L. nebulosa de Meij. ähnlich, von welcher Art nur das Männchen bekannt ist.

\section{Gynoplistia Westw.}

Gynoplistia melancholica Walk.

Waigeu, $y$ Januar 1910, $1 \sigma^{7}$.

Die Stirne ist bei dieser Art braungelb, desgleichen Untergesicht und Taster. Die 13 unteren Geisselglieder mit langem Anhang, die 2 unteren Anhänge nach unten gerichtet. Das Collare ist weisslich gelb. Thorax, Schildchen und Hinterrücken schwarz. Brustseiten schwarz, vorn und hinten und eine von der Flügelwurzel zum Bauch verlaufende Strieme gelblich. Hinterleib matt schwarz, der $1^{\text {te }}$ bis $6^{\text {te }}$ Ring mit gelbem Vordersaum, am $5^{\text {ten }}$ und $6^{\text {ten }}$ Ring ist dieser Saum sehr schmal. Hypopyg glänzend schwarz. Das Geäder und die Flügelzeichnung stimmt mit denjenigen von $G$. occipitalis n. sp. aus Neu Guinea, welche ich bald $\mathrm{zu}$ beschreiben hoffe, sehr überein, nur ist wenigstens beim vorliegenden Exemplar der Fleck auf der Basis der Radialader bedeutend grösser, der folgende, unter dem Stigma liegende, kleiner als bei der genannten Art, auch ist die Vorderrandzelle ganz schwarzbraun und diese Bräunung am Vorderrande setzt sich bis zur gebräunten Flügelspitze fort. Das einzig vorhandene Vorderbein ist nur an der Wurzel der Schenkel etwas gelblich. Schwinger schwarzbraun mit gelbem Stiel.

Körper- und Flügellänge $8 \mathrm{~mm}$.

Unter den übrigen aus dem Gebiete bekannten Arten dieser Gattung hat G. jucunda einen rotgelben Hinterleib, bei jurgissa $\sigma^{7}$ ist derselbe rotgelb mit schwarzer Spitze, beim $ᄋ$ schwarz, mit weissen Binden und gelber Spitze, bei fulviceps (nur das + bekannt) rotgelb mit schwarzer Wurzel und Spitze, bei insolita (ebenfalls nur das $q$ bekannt) ist es schwarz mit gelben Binden, die Stirne ist bei derselben jedoch nur vorn braunrot. Die Gattung ist in Australien reichlich vertreten.

\section{Dicranomyia Steph.}

Dicranomyia de-Beauforti n. sp. (Fig. 4).

.Saonek, Dezember, Januar, $\sigma^{\circ}$, .

$\sigma^{7}$. Kopf mattgrau; Fühler schwarzbraun, dick, die Glieder kurz gestielt, oben asymmetrisch verbreitert, an der Vorderseite stark vorspringend, kurzbehaart. Rüssel braungelb, Taster schwarzbraun.

Thorax braungelb, mit 3 sehr breiten dunkelbraunen Striemen, die seitlichen vorn abgekürzt; hinter der Quernaht grösstenteils dunkelbraun, nur am Rande heller, auch das Schildchen nur an den Seiten braungelblich. Brustseiten braun. Hinterrücken und Hinterleib 
dunkelbraun, wenig glänzend, aber etwas mehr als der Thorax, die Zange mässig gross, das $1^{\text {to }}$ Glied der Zangenarme relativ lang, das $2^{\text {te }}$ klein, auch der Bauch schwarzbraun.

Beine gelbbraun, die Schenkel an der Wurzel nur wenig heller. Flügel (Fig. 4) relativ breit, fast glashell, Stigma kaum angedeutet. Hilfsader weit vor dem Ursprung der Radialader in den Flügelrand mündend; die Radialader überhaupt kurz; auch die Discoidalzelle der Flügelspitze genähert, die Adern aus derselben etwa so lang wie die Zelle; hintere Querader an der Wurzel dieser Zelle. Schwinger gelb.

Körper- und Flügellänge $5,5 \mathrm{~mm}$.

ㅇ. Wie das Männchen, die Fühlerglieder weniger asymmetrisch. Legeröhre lang, die oberen Klappen schmal, gerade, stabförmig, auch die untere Klappe gerade.

Flügellange $\mathrm{c}^{\mathrm{a}} 5 \mathrm{\textrm {mm }}$.

\section{Mongoma Westw.}

Mongoma obscura n. sp. (Fig. 5).

Waigeu, 1 Januar 1910, 1 ○.

$\sigma^{7}$. Kopf samt Fühlern und Tastern schwarzbraun. Thorax einfarbig matt dunkelbraun; Brustseiten hellbraun, glänzend. Hinterleib matt schwarzbraun, kurzbehaart. Genitalien wenig vorspringend. Beine sehr lang und dünn, schwarzbraun, die Schenkel an der äussersten Spitze, die Schienen an der Spitze breit weiss, die Tarsen nach der Spitze hin allmählich etwas heller. Flügel (Fig. 5) glashell, Discoidalzelle vorhanden, aus derselben gehen 4 gerade Adern zunı Flügelrand. Schwinger schwarzbraun.

Körperlänge $6 \mathrm{~mm}$; Flügellänge $6,5 \mathrm{~mm}$.

Durch die Beinfarbe von den übrigen Arten aus dem Gebiete leicht zu unterscheiden,

\section{TIPULIDAE.}

\section{Tipula L.}

\section{Tipula sp.}

Ceram, Februar, 1 우.

Eine mit pallida Walk. verwandte Art von braungelber Farbe. Brustseiten vorn und der Thoraxrücken vorn am Rande dunkelbraun, auch die Quernaht in der Mitte von dieser Farbe; die beiden letzten Hinterleibsringe schwarzbraun, die Legeröhre glänzend rotgelb. Das Geäder wie bei pallida, die Gabel an der Discoidalzelle kürzer gestielt. Unter dem Stigma findet sich die Spur der hier bei pallida vorkommenden weissen Querlinie. Fühler abgebrochen.

Flügellänge $25 \mathrm{~mm}$.

2. Tipula umbrina Wied.

Waigeu, Januar, 10 .

3. Tipula omissinervis de Meij.

De MejJere, Nova Guinea V. Zoologie. 1906, p. \%1. (Tanypremna omissinervis).

Waigeu, Januar, 1 ㅇ.

\section{STRATIOMYIOAE.}

Negritomyia Big.

Negritomyia maculipennis Macq.

Ceram, Februar, 1 ç. 


\title{
XYLOMYIDAE.
}

\author{
Xylomyia Rond.
}

Xylomyia flavipes DoI.

Saonek, Januar, 2 우.

Diese Art ist inamoena Walk., wenigstens den von mir als diese Art bestimmten javanischen Stücken, sehr ähnlich und stimmt namentlich auch in dem Besitz gelber Hüften mit ihr überein. Die Thoraxbehaarung ist indessen mehr goldgelb; der Hinterleib grösstenteils gelbrot mit nur kurzen dunklen Rückenflecken, welche den Seitenrand bei weitem nicht erreichende Querbändchen darstellen; die Hinterschienen sind an der Aussenseite ganz schwarz, hinten und innen bis auf die Spitze gelb. Bei inamoena ist der Thorax weisslich behaart, der Hinterleib viel dunkler, die Hinterschienen sind aussen nur in der Endhälfte schwarz.

\section{LEPTIDAE.}

Chrysopilus Macq.

Chrysopilus opalizans n. sp. (Fig. 6).

Waigeu, Januar, 1 ㅇ.

․ Stirne glänzend schwarz, wie poliert, vorn mit Längsfurche. Wangen schwarz mit weisslichem Schiller. Untergesicht gewölbt und nach unten vorspringend, glänzend schwarz. Taster mattschwarz; Rüssel gelb mit schwarzer Spitze.

Thorax oben glänzend schwarz, am Seitenrand jederseits ein dreieckiges gelbes Fleckchen, welches hinten die Quernaht berührt. Schildchen ganz mattgelb, Brustseiten gelb mit 2 schwarzbraunen Querbinden, die vordere fängt vor der Flügelwurzel an und verläuft zu den Mittelhüften, die hintere schliesst die Brustseiten hinten ab. Hinterleib grösstenteils schwarzbraun, der Hinterrand des $1^{\text {ten }}$ und der Vorderrand des $2^{\text {ten }}$ Ringes schmal braungelb, namentlich an den Seiten. Hüften alle gelb, an den vorderen Beinen sind die Schenkel gelb, die Schienen und Tarsen braun. Hinterschenkel schwarzbraun, an Wurzel und Spitze gelb; Hinterschienen braungelb mit dunkler Spitze, Tarsen braun. Flügel (Fig. 6) braun gestreift, die Streifen mehr oder weniger längs den Adern verlaufend. 2te Hinterrandzelle breit. Die hellen Teile des Flügels irisieren schön ins Blaue. Schwinger schwarzbraun mit braungelbem Stiel.

Körperlänge $5 \mathrm{~mm}$.; Flügellänge $6 \mathrm{~mm}$.

Durch die erweiterte und opalisierende $2^{\text {te }}$ Hinterrandzelle stimmt diese Art mit vacillans. Walk. überein, welche aber einen grösstenteils gelben Thoraxrücken hat.

\section{BOMIBYLIIDAE.}

Argyramoeba Schin.

1. Argyramoeba leucostigma v. d. Wulp, syn. terminalis v. d. Wulp.

v. D. WuLp. Termész. Füz. XX̃I, p. 419.

Ceram, Februar, 1 o.

Kopf mattschwarz, schwarz behaart, Untergesicht graulich. Fühler schwarz, das $3^{\text {te }}$ Glied nierenförmig, besonders nach unten hin stark verlängert.

Thorax und Hinterleib schwarz, grösstenteils schwarz behaart, dazwischen goldgelbe Haare zerstreut; $1^{\text {tex }}$ Hinterleibsring an den Seiten mit längerer Behaarung, welche oben schwarz, mehr nach unten weisslich ist; hinter dieser Behaarung zeigt der Ring, am Seitenrande, ein Querbändchen schneeweisser, anliegender Behaarung; ein ebensolches findet sich an den Seiten des Hinterrandes des $5^{\text {ton }}$ Ringes. Die äusserste Hinterleibsspitze rötlich behaart, was indessen bei oberer Ansicht unter der vorhergehenden schwarzen Behaarung verdeckt ist. Beine ganz schwarz. Flügel fast ganz schwarz, nur der Aussenrand glasshell, dieser Teil innen zackig begrenzt, fast wie in van der Wulp's Figur angegeben. 
Nach VAN DRR WULP wären Schienen und Tarsen heller, mehr braungelb, der Hinterleib an den Seiten der Wurzel fuchsrot behaart. Vielleicht lag ihm das $\sigma^{\pi}$ vor.

2. Argyramoeba distigma Wied., var. trimaculata v. d. Wulp

Ceram, Februar.

THEREVIDAE.

Psilocephala Zett.

Psilocephala sp.

Saonek, Dezember, 1 Ex.

Eine mit Ps. indica v. d. W. verwandte Art; das Exemplar ist zur näheren Untersuchung nicht genügend gut conserviert.

\section{ASILIDAE.}

Leptogaster Meig.

Leptogaster rufithorax n. sp. (Fig. "y).

Waigeu, Januar, 2 ○ $\sigma^{7}$.

Stirne und Untergesicht dunkelbraun, mit gelblichem Tomente; Fühler rotgelb, die Borste dunkler, so lang wie der Fühler; Rüssel rotgelb; der Knebelbart aus wenigen gelben Borsten gebildet.

Thorax glänzend gelbrot mit gelben Borsten; Brustseiten braungelb, weisslich bestäubt. Hinterleib grösstenteils purpurschwarz, der Vorder- und Hintersaum der Ringe breit rotgelb, der $2^{\text {to }}$ Ring rotgelb mit purpurschwarzer breiter Binde vor der Spitze; der $6^{\text {te }}$ und $y^{\text {to }}$ Ring nur an der Wurzel schmal gelb; Hypopyg schwarz, die kurzen Anhänge zum Teil gelbbraun. Beine rotgelb, die Kniee sehr schmal schwarz, die Tarsen an der Spitze nur wenig dunkler, die Krallen schwarz. Flügel (Fig. 7) fast glashell, an der Flügelspitze der äusserste Flügelrand schmal schwarzbraun gesäumt; kleine Querader ungefähr in der Mitte der Discoidalzelle, die Gabel der $3^{\text {ten }}$ Längsader länger als ihr Stiel, die beiden Zinken fast parallel, die untere nur an der Spitze etwas zur oberen aufgebogen; Analzelle offen. Schwinger dunkelbraun mit gelbem Stiel.

Körperlänge $10 \mathrm{~mm}$; Flügellänge $6 \mathrm{~mm}$.

Leptogaster magnicollis Walk. von Ceram ist ebenfalls rotgelb, der Thorax zeigt jedoch vorn jederseits einen schwarzen. Flecken. Auch bei $L$. ferrugineus und longipes Walk. von Aru ist der Thorax rotgelb, beide Arten unterscheiden sich indessen durch dunklere Beine.

\section{Clinopogon Bezzi.}

Clinopogon albicapillus v. d. W.

De MeiJere, Nova Guinea V. Zool. 1906, p. \%5. (Stichopogon).

Saonek, Januar.

Die vorliegenden Stücke stimmen mit dem in "Nova Guinea" als diese Art bestimmten Exemplar überein. Letzteres habe ich seinerzeit mit der aus Java stammenden Type van DER Wulp's verglichen, sodass die Identität wohl angenommen werden darf. Die Flügel sind sehr wenig oder nicht gebräunt. Die Behaarung des Schildchens ist weiss.

Cl. Sauteri. Bezzi die Type der von BezzI in „Revisio systematica generis dipterorum Stichopopon, Ann. Mus. Nat. Hungar. VIII, 1910, p. 153" von Stichopogon abgetrennten Gattung, ist der vorliegenden Art offenbar sehr ähnlich, eine mediane Thoraxstrieme ist aber kaum angedeutet, auch ist die Analzelle nicht lang gestielt, wie es bei Sauteri der Fall sein soll. 
Astylopogon gen. n. (Fig. 8-10).

Von Dioctria-ähnlichem Habitus. Kopf kurz. Augen gross, die vorderen Fazetten bedeutend grösser. Ocellenborsten sehr kurz und dünn. 3 $3^{\text {tes }}$ Fühlerglied (Fig. 8) von länglicher Gestalt, länger als die beiden Wurzelglieder zusammen, vor der Spitze oben mit einem Dörnchen; ein Griffel ist nicht vorhanden. Untergesicht schmal, überall gleich breit gerade, also ohne Höcker, der Knebelbart nur aus wenigen Borstenhaaren gebildet. Rüssel kurz, wagerecht vorstehend. Thorax so lang wie breit, unbeborstet, mässig gewölbt. Metapleuren mit langen Borsten, Schildchen borstenlos. Hinterleib von schmaler Gestalt. Beine nicht besonders lang, Vorderschiene an der Spitze ohne Borste, nur mit einigen Härchen; Schenkel und Schienen mit mehreren Borstenhaaren; Hinterschenkel und -schienen (Fig. 9) wenigstens bei der vorliegenden Art mit je einer Haarbürste. Alle Metatarsen deutlich etwas länger als das nächstfolgende Glied. Pulvilli gut entwickelt. Flügel (Fig. 10) mässig breit; die erste Längsader schmiegt sich bald der Einmündung der Hilfsader an den Vorderrand an. Aus der Discoidalzelle treten nur 2 Adern zum Flügelrand, es sind also nur 4 Hinterrandzellen vorhanden, welche alle offen sind; auch die $3^{\text {te }}$ ist nicht an dem Flügelrande verengt und an der Wurzel nicht gestielt. Zwischen Discoidal- und $4^{\text {ter }}$ Hinterrandzelle eine kleine Querader vorhanden. Analzelle geschlossen. Alulae rudimentär.

Diese Gattung steht Habropogon nahe; sie unterscheidet sich namentlich durch den Fühlerbau, das Flügelgeäder, die Beinbewaffnung etc.

\section{Astylopogon Catharinae n. sp.}

Waigeu, Dezember, 1 o

Stirn und Untergesich hschwarzbraun, gelbbraun bestäubt; letzteres nur über dem Mundrand mit wenigen gelblichen Borstenhaaren. Fühler schwarzbraun. Rüssel glänzend schwarz; Hinterkopf braun bestäubt, nur unten mit einigen Härchen.

Thorax glänzend stahlblau, fast nackt, die Schultergegend und der Seitenrand sammetartig dunkelbraun. Schildchen metallisch purpurn; die Brustseiten schwarz, wenig glänzend; auch die Haare vor den Schwingern schwarz. Hinterleib stahlblau, dicht aber sehr kurz schwarz behaart. Hypopyg mässig gross; die Zangenarme sind seitlich comprimiert, gebogen, mit breiter, abgestutzter, nach unten vorgezogener Spitze. Beine dunkelbraun, Hüften und Trochanteren heller, gelbbraun; Schenkel und Schienen mit langen, gelben Borstenhaaren. An der Unterseite der Hinterschenkel findet sich eine sehr dichte, gleichmässig kurze, gelbe Behaarung, welche Wurzel und Spitze freilässt; eine ebensolche, aber etwas längere, trägt die Unterseite der Hinterschiene, mit Ausnahme der Wurzel. Flügel glashell, die Spitzenhälfte sehr schwach bräunlich. Kleine Querader am Ende des $1^{\text {ten }}$ Drittels der Discoidalzelle. Schwinger dunkelbraun mit gelblichem Stiel.

Körperlänge. $5 \mathrm{~mm}$; Flügellänge $4 \mathrm{~mm}$.

Es sei mir vergönnt, diese interessante Art der verdienstvollen Sammlerin dieser WaigeuAusbeute, Frau de Beaufort, zu widmen.

Laphria Meig.

1. Laphria notabilis Macq.

West-Ceram, Juni, van Dedem leg.

2. Laphria ferruginosa v. d. Wulp.

Ceram, Februar.

Maira Schin.

1. Maira spectabilis Guér.

Ceram, Februar; Waigeu, Januar. 
2. Maira hispidella v. d. Wulp.

Saonek, Januar.

3. Maira aenea F.

Ceram, Februar.

4. Maira hirta n. sp.

Ceram, Februar, 1 ơ ; 2 우.

Die Haare am $1^{\text {ten }}$ Hinterleibsringe sind bei diesen Exemplaren grösstenteils schwarz.

5. Maira nigropilosa $\mathrm{n}$. sp.

Ceram; Februar; Waigeu, Januar.

Beide letztgenannte Arten liegen mir auch von Neu-Guinea vor; die Beschreibung wird zusammen mit derjenigen weiterer neuen Arten dieser Gattung in „Nova Guinea”; Bd. IX erscheinen.

\section{Ommatius Wied.}

1. Ommatius fulvidus Wied.

West-Ceram, Juni, van Dedem leg.

2. Ommatius bisetus a. sp. (Fig. 11).

Ceram, Februar, $1 \sigma^{7}, 1$ \%.

○. Stirne gelbbraun bestäubt. Fühler schwarzbraun, das $3^{\text {te }}$ Glied etwas heller, dunkelbraun, eiförmig. Untergesicht gelblich, jederseits mit 3 langen, schwarzen Borsten, darunter der weisse Knebelbart. Rüssel glänzend schwarz, Taster und Hinterkopf weisslich behaart.

Thorax schwarzbraun, gelblich bestäubt, fast nackt, hinten nur jederseits eine, ziemlich starke, schwarze Dorsocentralborste. Schildchen von der Farbe des Thorax, mit 2 bräunlichen, ziemlich schwachen Endborsten. Brustseiten weissgrau bestäubt, der Haarschopf vor den Schwingern weiss. Hinterleib schwarzbraun, die Einschnitte der mittleren Segmente sehr schmal gelb, die Behaarung äusserst kurz, schwarz, die zerstreuten Haare vor den Einschnitten und an den Seiten gelb. Copulationsorgan (Fig. 11) ziemlich dick; die Zangenarme stark verdickt, gerade, an der Spitze oben mit einem aus einigen dicht neben einander stehenden Borsten gebildeten Anhang, unten mit einem nach unten gerichteten Zahn. Vorderhüften gelb, die hinteren grau; die vorderen Beine gelb, die 4 letzten Tarsenglieder aber schwarzbraun; die Hinterbeine sind schwarzbraun, nur ist die Wurzelhälfte der Hinterschenkel und-schienen gelb; die Beborstung ist an den gelbgefärbten Teilen ebenfalls gelb, im Übrigen schwarz.

Flügel glashell, die Spitze nur.wenig dunkler, die kleine Querader etwas hinter der Mitte der Discoidalzelle, die Gabe] der $3^{\text {ten }}$ Längsader bedeutend länger als.ihr Stiel. Schwinger gelb.

Körperlänge $7 \mathrm{~mm}$; Flügellänge $5,5 \mathrm{~mm}$.

o. Das vorliegende Weibchen hat ganz schwarzbraune Fühler; auch die Endborsten des Schildchens sind schwarz. Diese Art dürfte $O . \therefore$ suffusus v. d. W. ähnlich sein, dessen vordere Schenkel und Schienen aber an der Spitze schwarz sein sollen.

Sie sieht auch in vielen Hinsichten $O$. calvus de Meij. ${ }^{1}$ ) aus Java sehr ähnlich, so u. a. durch die 6 schwarzen Untergesichtsborsten und die geringe Thoraxbeborstung, desgleichen

1) De MeIJere. Studien über südostasiatische Dipteren VI, Tijdschr. v. Entom. LiV, 1911, p. 319. 
in der Beinfärbung. Die männlichen Copulationsorgane zeigen indessen bedeutende Unterschiede, auch hat calvus ein helleres (rotgelbes) $3^{\text {tes }}$ Fühlerglied und es finden sich beim $\sigma^{7}$ an der Unterseite der Vorderschenkel 6 sehr starke, gerade, gelbe Borsten. Bei bisetus besteht diese Beborstung aus langen Borstenhaaren, dagegen sind die Borsten der Vorderschienen stärker als bei calvus. Die Borste an der Aussenseite, nahe der Basis, ist gleichfalls bei bisetus stärker und dunkel, bei calvus weiss. Das $ᄋ$ von calvus hat an den Vorderschenkeln nur dünne Borstenhaare, auch hier finden sich an den Schienen nur weisse Borstenhaare, wăhrend das $q$ von bisetus an der vom Körper abgewandten Seite dieser Schienen 2 lange schwarze Borsten trägt und auch die kurze Aussenborste schwarz ist.

\section{Ommatius nigripes n. sp.}

Waigeu, Januar, 1 or.

$\sigma^{7}$. Stirne schwarzbraun, dunkelbraun bestäubt; Fühler ganz schwarz, das $3^{\text {te }}$ Glied kurz eiförmig. Untergesicht schmal, weisslich behaart, mit einem Stich ins Gelbe, die Beborstung ganz schwarz. Rüssel glänzend schwarz, Taster schwarzbehaart. Behaarung von Hinterkopf und Backen weisslich.

Thorax schwarzbraun; etwas glänzend, zerstreut dunkel behaart, die Beborstung spärlich, es sind nur jederseits 2 schwache schwarze Dorsocentralborsten bemerkbar. Schildchen schwarzbraun mit 2 kurzen schwarzen Endborsten. Brustseiten schwarz, dünn braun bereift, hinten . mit einigem weissen Schiller. Hinterleib schmal, schwarzbraun, nach hinten etwas erweitert, kurz schwarz behaart, die Copulationsorgane klein, die Zangenarme kurz und, dick, wenig gebogen. Beine schwarz, nur die Aussenseite der vorderen Schienen braun, die Beborstung schwarz.

Flügel in der Wurzelhälfte glashell, die Spitzenhälfte gebräunt; Gabel der 3 ten Längsader. etwas länger als ihr Stiel; kleine Querader etwas hinter der Mitte der Discoidalzelle; diese Zelle schmal, die obere Ader aus derselben an der Wurzel aufwärts gebogen. Schwinger gelb.

Körperlänge $12 \mathrm{~mm}$; Flügellänge $5 \mathrm{~mm}$.

\section{EMPIDIDAE.}

\section{Syndyas Walk.}

Syndyas aterrima n. sp. (Fig. 12).

Ceram, Februar, 1 o.

․ Ganz glänzend schwarz. Ocellenhöcker mit 2 kurzen schwarzen Borsten. Augen auf der Stirn zusammenstossend, Untergesicht sehr schmal, linienartig. Fühler mässig lang, schwarz, das $3^{\text {to }}$ Glied länglich oval, mit schwarzer, etwas excentrisch nach oben eingepflanzter Borste, welche bedeutend länger ist als die Fühler. Der Rüssel und die schmalen Taster glänzend schwarz. Der Thorax lang, aber nicht dicht behaart, die Behaarung ziemlich dunkel, aber mit fahlgelbem Schiller. Brustseiten dünn braun bereift. Von hinten gesehen zeigt auch der hintere Teil des Thorax eine rötlich braune Bestäubung. Besondere Dorsocentralborsten sind zwischen der Behaarung nicht erkennbar. Schildchen mit 2 schwarzen Endborsten. Präsuturale vorhanden, schwarz. Am Hinterleib ist die Behaarung heller als am Thorax, in gewisser Richtung weiss, ebenfalls ziemlich lang; der Bauch ist mattschwarz.

Auch die Beine sind ganz schwarz, ziemlich lang schwarz behaart. Hinterschenkel in der Endhälfte dentlich, aber nicht stạk, kolbenartig verdickt; ausser der kürzeren Behaarung mit weit auseinander stehenden langen Borstenhaaren, Hinterschienen gleichfalls am Ende kolbig, aussen mit einigen langen Borstenhaaren; Mittelschienen aussen in der Mitte mit einem längeren Haar. Vorderschienen namentlich in der. Wurzelhälfte etwas verdickt, an der Innenseite abgewandt mit ziemlich langer und dichter Behaarung. Flügel (Fig. 12) bräunlich tingiert, ausserst kurz behaart; das Stigma dunkelbraun, die $3^{\text {to }}$ und $4^{\text {te }}$ Längsader gerade und parallel, Discoidalzelle lang aber schmal. Schwinger schwarzbraun.

Körperlänge c c $^{\mathrm{a}} \mathrm{mm}$; Flügellänge $2,5 \mathrm{~mm}$. 


\section{DOLICHOPODIDAE.}

Psilopus Meig. ${ }^{1}$ )

1. Psilopus crinicornis Wied.

Waigeu, Dezember, 1 o

2. Psilopus rectus Wied.

DE Meijere, Studien IV. Tijdschr. v. Entom. LIII, p. 81.

Sa.onek, Januar.

Diese Art kennen wir jetzt von Sumatra, Krakatau und. Saonek; unter den zahlreichen, von JacoBson auf Java erbeuteten Arten dieser Gattung findet sie sich nicht.

\section{Psilopus benedictus Walk.}

Ceram, Februar, 1 o. Ceram, Juni, 1 o; van Dedem leg.

Bei beiden Exemplaren sind die Hinterschienen an der Spitze, namentlich oben, breit verdunkelt, breiter als dies bei den mir vorliegenden Neu-Guinea-Exemplaren der Fall ist.

\section{Psilopus aeneus $\mathrm{F}$.}

Waigeu, Dezember; Saonek, Januar.

5. Psilopus pectoralis n. sp. (Fig. 13).

Waigeu, Januar, 1 \%.

o. Stirne metallischgrün, ohne Orbitalborsten. Fühler kurz, braun, das $1^{\text {to }}$ Glied mit Ausnahme der Oberseite braungelb, das $3^{\text {to }}$ nur wenig länger als breit, stumpf, mit ziemlich langer, schwarzer, vor der Spitze eingepflanzter Borste. Untergesicht grün, gelblich bestäubt; Rüssel gelb.

Thorax oben glänzend metallisch grün, mit 2 inneren und hinten 2 äusseren Dorsocentralborsten. Schildchen mit 2 Borsten, grün, mit blauem Rande, auch der Hinterrücken blau. Brustseiten ganz rotgelb. Hinterleib metallich grün, namentlich an der Basis weiss bestäubt, die Seitenränder der 5 ersten Ringe gelb, desgleichen der Bauch, überdies in der hinteren Halfte schwarze Querbinden an den Einschnitten, von beträchtlicher Breite. Hypopyg (Fig. 13) gelb, mit langen, fadenförmigen, dicht behaarten Fortsätzen von derselben Farbe. Beine ganz gelb, nur die Tarsen dunkler; Vorderhüften mit 3 gelben Borsten; Vorderbeine nackt; Mittelschenkel unten ziemlich lang schwarz gewimpert, Hinterschenkel unten nur sehr kurz und zerstreut behaart; die langen Mittelschienen aussen mit 2 kurzen schwarzen Börstchen; Hinterschienen mit mehreren kurzen Börstchen. Flügel etwas gebräunt; 1 to Längsaner sehr kurz, 2te sehr lang, Spitzenquerader in der unteren Hälfte ziemlich stark aber gleichmässig gebogen, fernerhin fast gerade, hintere Querader nicht besonders stark S-förmig geschwungen. Schwinger braungelb; Schüppchen gelb, gelb gewimpert.

Körper- und Flügellänge $4,5 \mathrm{~mm}$.

6. Psilopus obscuripennis n. sp. (Fig. 14, 15).

Waigeu, Januar, 10 .

ऽ. Stirne blau mit grünlichem Schimmer, an den Seiten mit zahlreichen schwarzen Haaren, worunter am Augenrande ein Paar längere, borstenartige auffallen. Fühler schwarz,

1) In den »Studien über südostasiatische Dipteren" habe ich die hieher gehörigen Arten als Agonosoma-Arten aufgeführt. Den nach dem Catalogus Dipterorum, Vol. VI, wieder zulässigen Namen Psilopus Meig. benutze ich jetzt gerne wieder. 
das $3^{\text {to }}$ Glied relativ kurz, eiförmig, mit excentrisch nach oben verschobener schwarzer Spitzenborste von ziemlicher Länge. Untergesicht blau, stellenweisse grün, Taster schwarz, schwarz behaart; Rüssel braun.

Thorax dunkel purpurblau, dünn dunkelbraun bereift; 3 innere Dorsocentralborsten, 1 äussere, vor letzterer einige kurze Härchen. Schildchen mit 4 Borsten, die äusseren bedeutend kürzer. Brustseiten dunkel purpurn bis schwärzlich, dünn weiss bereift. Hinterleib purpurn mit grünen Reflexen, mit breiten mattschwarzen Querbinden, lang schwarz beborstet; Hypopyg (Fig. 15) schwarzbraun, die äusseren Anhänge lang fadenförmig, dicht behaart, die nächstinneren stabförmig, abgestutzt, die folgenden mit relativ starken, dornartigen Borsten.

Beine ganz schwarz; Vorderschenkel unten mit langen, schwarzen Borsten; Vorderschienen aussen mit 2 kurzen Börstchen. Mittel- und Hinterschenkel unten weitläufig schwarz behaart; Mittelschienen aussen und innen mit einer schwarzen Borste; Hinterschienen aussen mit einigen kurzen schwarzen Borsten. Flügel (Fig. 14) glashell, am Vorderrande breit gebräunt, auch die Adern grösstenteils schwarzbraun gesäumt. 2te Längsader lang; Spitzenquerader in der Mitte stark, aber doch nicht eckig gebogen, im unteren und oberen Teil gerade; hintere Querader nur wenig S-förmig geschwungen. Schwinger schwarzbraun, Schüppchen desgleichen, schwarz behaart.

Körper- und Flügellänge $4,5 \mathrm{~mm}$.

Diese Art sieht durch die düstere Körper- und Flügelfärbung Psilopus nigrolimḃatus de Meij. aus Neu-Guinea ähnlich, von welchem nur das Weibchen bekannt ist. Bei diesem sind die Hinterleibsbinden grün; die Vorderschienen sind gelblich, die Vorderschenkel unten nur kurz behaart.

\section{\%. Psilopus ceramensis n. sp. (Fig. 16, 19).}

Ceram, Februar.

$\sigma^{7}$. Stirne glänzend metallisch blaugrün, zart braun bereift, an Stelle der Orbitalborste ein zartes Härchen. Fühler schwarz, das $3^{\text {te }}$ Glied so lang wie die beiden Wurzelglieder zusammen, mit ziemlich langer, schwarzer Endborste. Hintergesicht metallisch grün, was oben bisweilen ins Kupferrötliche, unten ins Blaue zieht. Rüssel dunkelbraun.

Thorax grün, ziemlich matt, der Vorder- und Seitenrand matt kaffeebraun; innere Dorsocentralborsten 3 ; äussere binten 2 . Schildchen blaugrün bis blau, mehr glänzend, mit 2 Borsten. Brustseiten grösstenteils grün, weiss bestäubt, oben und vorn kaffeebraun. Hinterleib metallisch grün, mit breiten, schwarzen Vorder- und Hinterrandsäumen; die dadurch hervorgerufenen schwarzen Querbinden breiter als die metallisch grünen, die Behaarung z. T. weiss, die Borsten vor den Einschnitten schwarz. Hypopyg (Fig. 1\%) ziemlich klein, schwarz, die Anhänge kurz, die äusseren etwas nach aussen gebogen, schwarz behaart, in der Mitte mit Gabelast. Hüften und Schenkel schwarz; Schienen braungelb, an der Spitze dunkel, Tarsen schwarzbraun. Mittelschenkel unten mit einigen hellen Borsten. An den. Vorderschenkeln unten 4 schwarze Borsten; Hinterschenkel nur mit kurzen, weissen Härchen. Vorderschienen aussen mit 3 schwarzen Borsten; Mittelschienen lang, mit 1 Borste an der Vorderseite, nahe der Wurzel, und 1 Borste an der Aussenseite dicht vor der Mitte; Hinterschenkel nur mit kurzen Börstchen. Flügel (Fig. 16) bräunlich tingiert, am Hinterrande heller, 1 to Längsader kurz, $2^{\text {te }}$ sehr lang, ihre Spitze derjenigen der dritten genähert; Spitzenquerader lang, sanft gebogen; hintere Querader stark S-förmig geschwungen, länger als ihre Entfernung von der Beugung der $4^{\text {ten }}$ Längsader. Schwinger dunkelbraun; Schüppchen schwärzlich, mit hellen Wimpern.

Körper- und Flügellänge $6 \mathrm{~mm}$.

\%. Stirne jederseits mit einer schwarzen Orbitalborste; Untergesicht dicht weisslich bestäubt. Dorsocentralborsten wie beim Männchen. Hinterleib mit schmäleren schwarzen Querbinden. Vorderbeine mit längeren Borsten als beim Männchen; Vorderschienen aussen mit 3, innen mit 1 langer Borste. Mittelschienen aussen mit 2, innen mit 3 langen Borsten; Hinterschienen mit 2 kurzen Börstchen an der Aussenseite. 
8. Psilopus albicinctus n. sp. (Fig. 18).

Waigeu, Januar, $2 \sigma^{\top} \sigma^{x}$.

$\sigma^{7}$. Stirne metallisch grün mit tiefblauem Schiller; 1 schwarze Orbitalborste vorhanden. Fühler schwarz, das $3^{\text {te }}$ Glied dreieckig, mit mässig langer, schwarzer Endborste. Untergesicht metallisch blaugrün, zart gelblich bereift. Rüsselspitze braungelb. Thorax metalliṣchgrün, besonders vorn matt kaffeebraun bestäubt. 2 innere und hinten 1 äussere Dorsocentralborste vorhanden; vor letzterer noch einige schwache Härchen. Brustseiten metallischgrün, wenig bereift. Schildchen mit 2 Borsten. Hinterrücken purpurblau; der $1^{\text {to }}$ Hinterleibsring schwärzlich; der $2^{\text {te }}$ weissbestäubt; die 5 folgenden Ringe sind metallischgrün, zum Teil mit rötlichem Kupferschiller und mit breiten, matt schwarzbraun bestäubten Vorderrändern. Hypopygium (Fig. 18) klein, schwarzbraun, die Anhänge von unbedeutender Grösse.

Beine braun, die hinteren Schenkel schwarzbraun, die Vorderschenkel in der Endhälfte heller, mehr gelblich; desgleichen die Vorderschienen. Beine unbeborstet; Schenkel unten weissbeháart, die Hinterschenkel am längsten. Letztes Tarsenglied der Vorderbeine etwas verbreitert. Flügel glashell, die Spitzenquerader zunächst zurücklaufend, mit fast eckiger Biegung, nach welcher sie gerade zum Rande verläuft; hintere Querader steil, fast gerade. Schwinger und Schüppchen samt Wimpern dunkelbraun. Beim $2^{\text {ten }}$ Exemplar zieht der Thorax hinten stark ins Blaue.

Die Art zeigt grosse Übereinstimmung mit Ps. fluminis n. sp. aus Süd-Neu-Guinea, welche Art indessen gelbe Schenkel besitzt; auch ist die weisse Bestäubung an der Hinterleibsbasis bei weitem nicht so auffällig.

9. Psilopus saonekensis n. sp. (Fig. 19, 20).

Saonek, Dezember, Januar.

○. Stirne purpurblau, an Stelle der Orbitalborsten einige helle Härchen. Fühler schwarz, das $3^{\text {te }}$ Glied schmal dreieckig, mit ziemlich langer schwarzer Endborste, die äusserste Spitze der Borste weiss. Untergesicht blaugrün, zart weiss bereift.

Thorax metallischgrün mit blanen Reflexen, wenig glänzend; 4 innere Dorsocentralborsten vorhanden, hinten 2 äussere. Brustseiten grün, grauweiss bestäubt; Schildchen blau, mit 4 Borsten, die äusseren schwach und halb so lang wie die mittleren. Hinterleib metallisch grün, die Vorder- und Hinterränder schwarz, die schwarzen Querbinden ungefähr so breit wie die grünen. Hypopyg (Fig. 20) schwarz; die äusseren Anhänge schmal, etwas gebogen, aussen behaart.

Beine ganz schwarz, Vorderhüften weissbehaart, auch an der Unterseite der Vorderschenkel die Borsten von weisser Farbe; Vorderschienen aussen mit 3 nicht langen schwarzen Borsten. Mittelschenkel unten nur mit weissen Härchen; Mittelschienen aussen nahe der Wurzel mit einem Börstchen. Hinterschenkel unten weiss gewimpert; Hinterschienen ohne längere Beborstung. Flügel (Fig. 19) glashell, 1te Längsader kurz, 2te sehr lang; Spitzenquerader gleichmässig gebogen, die Spitzenzelle fast am Rande geschlossen. Hintere Querader S-förmig gekrümmt. Schwinger schwarzbraun, Schüppchen dunkelbraun, hellgewimpert.

Körper- und Flügellänge $4,5 \mathrm{~mm}$.

Ein $2^{\text {tes }}$ Exemplar hat an Kopf und Thorax eine weit mehr grüne Färbung, die Stirne und das Untergesicht sind fast ganz grün, der Thorax zieht hinten etwas ins Blaue.

․ Das einzige, mir vorliegende Weibchen hat die Färbung des erstbeschriebenen Männchens, die Fühlerborste ist kürzer und an der Spitze nicht weișs; die Stirne besitzt jederseits eine schwarze Orbitalborste; 3 innere und 4 äussere Dorsocentralborsten sind vorhanden; die Mittelstrieme des Thorax ist grün, jederseits breit blau begrenzt. Am Hinterleib sind die schwarzen Binden bedeutend schmäler. An den Beinen sind die schwarzen Borsten der Vorderschienen länger; die Mittelschienen zeigen aussen 4, innen 2 schwarze Borsten: an den Hinterschienen findet sich aussen nahe der Wurzel eine schwarze Borste; die weisse Bewimperung an der Unterseite der Hinterschienen ist etwas kürzer. Die hintere Querader ist weniger geschwungen.

Körper- und Flügellänge $4 \mathrm{~mm}$. 
10. Psilopus sericeus n. sp. (Fig. 21, 22).

Saonek, Januar, 1 o und mehrere $ᄋ$ ㅇ.

$\sigma^{7}$. Stirne bläulich-grün, mässig glänzend, an den Seiten mit zahlreichen gelben Haaren, ohne Orbitalborsten. Fühler schwarz, das $3^{\text {te }}$ Glied schwarzbraun, kaum länger als breit mit für diese Gattung kurzer, schwarzer, dorsal eingepflanzter Borste. Untergesicht metallisch grün mit blauen Reflexen, unten zart gelblich weiss bereift.

Thorax grün, kaum glänzend, die Schultergegend kupferrötlich, was sich hinten in eine braune Strieme am Thoraxrande fortsetzt; 3 innere und 4 äussere Dorsocentralborsten vorhanden; von den letzteren sind jedoch jederseits die 2 vorderen schwach entwickelt. Schildchen mehr glänzend, blau, mit 2 Endborsten und jederseits einem schwachen Haare. Brustseiten metallisch grün, weiss bereift. Hinterleib metallisch grün, grösstenteils gelblich grün, mit schwarzen Querbinden, welche breiter sind als die grünen Zwischenräume; Hypopyg (Fig. 22) schwarzbraun, die Anhänge mässig lang.

Hüften und Schenkel schwarz; die vorderen Schenkel an der äussersten Spitze gelb; Schienen gelb, die hinteren im Enddrittel verdunkelt; Tarsen schwarzbraun, an den vorderen der Metatarsus noch grösstenteils gelblich. Vorderhüften weiss behaart, vorn im unteren Teile mit einigen weissen Borstenhaaren; Vorderschenkel unten weiss behaart, die Haare in der Wurzelhälfte lang; Mittelschenkel kürzer behaart; Hinterschenkel unten mit Ausnahme des Spitzendrittels weitläufig lang weiss behaart. Schienen ohne längere Borsten. Flügel (Fig. 21) glashell; am Vorderende und um die Adern schwach gebräunt; Spitzenquerader seicht gebogen; hintere Querader schief gestellt, etwas geschwungen; die $1^{\text {to }}$ Längsader mündet iń der Mitte des Vorderrandes. Schwinger und Schüppchen samt Wimpern schwarzbraun.

Körper- und Flügellänge $3,5 \mathrm{~mm}$.

‥ Auf der Stirne jederseits 1 starke Orbitalborste vorhanden. Thorax fast mattgrün mit blauen Reflexen, der Seitenrand nicht braun; Brustseiten weiss bestäubt. Hinterleib metallisch grün, ohne schwarze Querbinden; von der Seite betrachtet zeigt der Hinterleib; wie der Thorax, blauen Schimmer; die Behaarung an der Unterseite der Hinterschenkel kürzer. Flügel ganz glashell; Spitzenquerader gleichmässig gebogen, bei den meisten Exemplaren ist die Spitzenzelle am Rande geschlossen, bei einigen, wie beim $\sigma$, schmal offen.

Körper- und Flügellänge $3 \mathrm{~mm}$.

Der Hinterleib des $Q$ ist bisweilen gelblich grün, sogar mit kupferrötlichen Reflexen.

$$
\text { 11. Psilopus waigeensis n. sp. (Fig. 23, 24). }
$$

Waigeu, Dẹember, Januar.

$\checkmark$. Stirne metallisch blau-grün, zart weisslich bereift; an Stelle der Orbitalborste ein feines schwarzes Härchen. Fühler schwarzbraun, das 3to Glied eiförmig, mit mässig langer schwarzer Endborste. Untergesicht grün, oben blaugrün und kaum bestäubt, unten mit grauweisser Bestäubung; Rüssel rotgelb.

Thorax metallisch blaugrün, am Seitenrande z. T. kupferrötlich; 3 innere und hinten 2 äussere Dorsocentralborsten. Schildchen von der Farbe des Thorax, mit 2 Borsten; mehr nach aussen jederseits ein winziges schwarzes Härchen; Brustseiten grün, stellenweise blau, weiss bereift. Hinterleib glänzend metallisch grün, mit schmalen, schwarzen Querbinden. Hypopyg (Fig. 24) schwarz, die äusseren Anhänge kurz, an der 'Spitzè mit einem längeren Haar, die inneren länger, an der Spitze verbreitert; neben diesen noch je ein dünner, stabförmiger, am Ende zugespitzter Fortsatz von gleicher Länge.

Vorderhüften gelb, an der Spitze - mit 3-4 gelben Borsten, die hinteren Hüften grau; Beine "im übrigen gelb, die Kniee der Hinterbeine braun, die Tarsen allmählich ins Braune verdunkelt. Die Schenkel unten núr kurż gelb behaart; Vorderschienen aussen nahe der Basis mit einer kurzen schwarzen Borste; Mittelschienen vorn mit 3, aussen mit 2 kürzeren Borsten'; Hinterschenkel aussen mit mehreren ziemlich langen Borsten. Flügel (Fig. 23) fast glashell, namentlich unter der distalen Hälfte des Vorderrandes leicht gebräunt, 1 te Längsader kurż, 
$2^{\text {te }}$ lang; Spitzenzelle offen, die Spitzenquerader in der unteren Hälfte stark, aber doch nicht fast eckig gebogen, weiterhin fast gerade; hintere Querader sehr schief gestellt, schwach geschwungen. Schwinger gelb; Schüppchen dunkelbraun, gelb gewimpert.

Körper- und Flügellänge $5,5 \mathrm{~mm}$.

o. Stirne mit 1 schwarzen Orbitalborste, Untergesicht etwas dichter weisslich bestäubt als beim Männchen; Farbe von Stirne und Thorax meistens mehr gelblich grün; Dorsocentralborsten des Thorax wie beim Männchen; Hinterleib mit schmalen schwarzen Querlinien. Vorderschienen aussen mit 2, hinten mit 2 kurzen Borsten; Mittelschienen vorn mit 3, aussen und hinten mit je 2 schwarzen Borsten; Hinterschienen mit 2 Reihen schwarzer Borsten. Flügelgeäder fast wie beim Männchen, die hintere Querader weniger schief und fast gerade.

Körper- und Flügellänge $4,5 \mathrm{~mm}$.

\section{Psilopus pallidipes n. sp.}

Waigeu, Dezember, 1 o ; Januar 1 o.

Die Beschreibung dieser Art, welche mir auch von. Süd-Neu-Guinea vorliegt, erscheint in "Nova Guinea" IX.

\section{Psilopus sp.}

Saonek, Januar, 1 o.

Mit Ps. waigeensis nahe verwandt, die Beine von gleicher Färbung. Er unterscheidet sich durch den Besitz von 5 äusseren Dorsocentralborsten (die vorderen 3 kürzer als die 2 hinteren), ferner durch die Beinbewaffnung; die Vorderschenkel zeigen unten eine Reihe gelber Borsten, von welchen namentlich die 2 hintersten sehr lang sind; die übrigen werden nach der Spitze des Schenkels zu allmählich schwächer und kürzer; Vorderschienen nur aussen mit 3 schwarzen Borsten, welche von beträchtlicher Länge sind; an den Hinterschienen ist die Beborstung weniger entwickelt als bei waigeensis; es zeigen sich nur aussen 2 schwarze Borsten.

Ausserdem liegen noch ein Paar weibliche Stücke weiterer Arten vor, welche einstweilen am besten unbeachtet bleiben.

\section{Bestimmungstabelle der oben angeführten Aiten.}

1. Brustseiten gelb

2. Flügel glashell, nur mit schwarzem Punkte an der Spitze ... . Ps. rectus Wied.

Flügel von anderer Färbung. . . . . . . . . . . . : . . . 3

3. Flügel mit dunkler Zeichnung oder überhaupt gebräunt . . ... 4

Flügel glashell . . . . . . . . . . . . . . .

4. Spitzenhälfte fast ganz verdunkelt, Wurzelhälfte mit 2 dunklen Fleckchen . . . . . . . . . . . . . . . . . .

Auf der Spitzenhälfte ein deutlicher dunkler Wisch $\cdot \cdot \cdot \cdot \cdot \cdot$ :

Flügel am Vorderrande und längs den Adern intensiv dunkel;

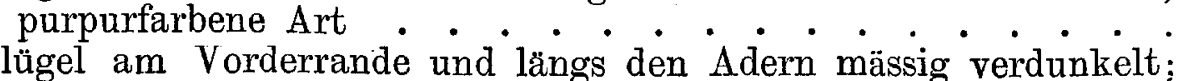

grüne Art . . . . . . . . . . . . . .

5. Schenkel schwarz. . . . . . . . . . . . . . . . . .

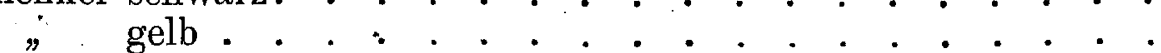

6. Spitzenquerader fast eckig, zunächst zurücklaufend. . . . . .

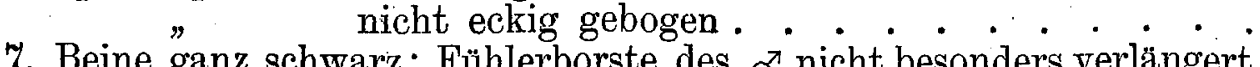
Schienen z. T. gelb. . . . . . . . . . . . . . . . • 8. Fühlerborste des $\sigma^{r}$ viel länger als der Körper . . . . . . .

9. Hüften gelb, Vorderhüften mit einer vollstandigen Reihe gelber $\dot{B} \cdot \dot{\cdot}$ Hintere Hüften dunkel, Vorderhüften nur an der Spitze mit Borsten

Ps. aeneus $\mathrm{H}$.

Ps. benedictus Walk.

Ps. obscuripennis $\mathrm{n}$. sp.

Ps. ceramensis n. sp. 6 $\mathbf{9}$
$\mathbf{9}$

B. albicinctus n. sp. 7

Ps. saonekensis n. sp. 8

Ps. crinicornis Wied.

Ps. sericeus n. sp.

Ps. pallidipes n. sp.

Ps. waigeensis n. sp. 
Diaphorus Meig.

1. Diaphorus maurus Ost. Saek.

Ceram, Februar.

2. Diaphorus plumicoñnis n. sp.

Ceram, Februar, 1 o $0^{7}$.

Diese Art liegt mir auch aus Süd-Neu-Guinea vor; sie wird in „Nova Guinea" IX beschrieben werden.

\section{SYRPHIDAE.}

Eristalis Latr.

1. Eristalis inscriptus Dol.

Ceram, i o.

$3^{\text {ter }}$ und $4^{\text {ter }}$ Hinterleibsring mit je 3 Flecken, welche mässig gross und von einander schmal getrennt sind.

2. Eristalis splendens Le Guill.

Ceram, Februar.

3. Eristalis arvorum Fabr.

Ceram, Februar.

Baccha Fabr.

Baccha pulchrifrons Aust.

Waigeu, 1 옹, Januar.

Paragus Latr.

Paragus serratus F.

Ceram, Februar.

Syrphus Fabr.

Syrphus (Asarcina) Birói Bezzi.

Ceram, Februar.

Melanostoma Schin.

Melanostoma planifacies Macq.

Ceram, Februar, $2 \sigma^{\pi}$.

\section{CALOBATINAE.}

Nerius Fabr.

Nerius annulipes Dol.

West-Ceram, van Dedem leg. 
Angitula Walk.

Angitula oyanea.

Waigeu, Januar.

Calobata Meig.

1. Calobata tipuloides Walk. (?)

Waigeu, Januar, 1 ㅇ.

Mit einigem Zweifel bringe ich das vorliegende Exemplar zu dieser Art. Von einem $\sigma^{7}$ aus Neu-Guinea unterscheidet es sich durch das noch viel mehr vorspringende Untergesicht; auch sind die Beine etwas heller, die Mittelschenkel z.B. an der Wurzel unten und an der Spitze breit gelb ohne scharfe Grenzen, während diese beim $\sigma^{\gamma}$ schwarz sind mit gut abgegrenztem weissem Ring vor der Spitze.

\section{Calobata nigripes v. d. Wulp.}

Ceram, Februar.

\section{Calobata albimana Dol.}

Waigeu, October; Ceram, Februar.

Eurybata Ost. Sack.

Eurybata tenuis Dol.

West-Ceram, 1 o, van Dedem leg.

Das Untergesicht, springt kegelförmig vor, die Fühlerborste ist beiderseits mässig lang gefedert. Stirnstrieme mattschwarz, in der Mitte etwas verengt. Periorbiten glänzend rotbraun, den Vorderrand der Stirne nicht erreichend, mit 2 Orbitalborsten. Vordere Stirnpartie mattgelb, die mattschwarze Medianstrieme erreicht den Vorderrand nicht ganz. Fühler rotgelb. Untergesicht unter den Fühlern mattbraun, der vorspringende untere Teil glänzend schwarzbraun. Rüssel braungelb.

Thorax braunrot mit dunklerer Mittelstrieme, das Schildchen ins Stahlblaue schillernd. Brustseiten rot mit einer sich von den Vorderhüften bis zum hinteren Rand des Sternopleurons erstreckender, nach hinten verbreiteter, weiss bestäubter Strieme; Sternopleuren mit einer Reihe von 4 Borstenhaaren. Hinterleib dunkelrotbraun bis schwarzbraun. Beine rotgelb, die Tarsen an der Spitze nur allmählich etwas verdunkelt. Flügel intensiv gebräunt, mit viereckigem, glashellem Fleck zwischen der $2^{\text {ten }}$ und $3^{\text {ten }}$, und zwischen der $3^{\text {ten }}$ und $4^{\text {ten }}$ Längsader; auch die $2^{\text {te }}$ Hinterrandzelle grösstenteils und die Flügelspitze bis zur Spitze der $2^{\text {ten Längs- }}$ ader glashell. 1 te Hinterrandzelle breit offen. Schwinger gelblich mit schwarbraunem Stiel.

\section{LAUXANIINAE.}

\section{Lauxania Latr.}

\section{Lauxania laticosta Thoms.}

De Mejuere. Studien II. Tijdschr. v. Entom. LI, p. 146.

Ceram, Februar; Kajeli, Buru, Dezember.

2. Lauxania signatifrons Kertész.

Waigeu, 1 Ex. 
3. Lauxania aff. Beckarii Kertész.

Waigeu, 1 Ex.

Wie Beckarii mit je 2 schwarzen Flecken am $4^{\text {ton }}-6^{\text {ton }}$ Ringe, aber die Flügel mit schwächeren Säumen um die Queradern und mit wenig gezeichneter Spitze.

\section{LONCHAEIDAE.}

Lonchaea Fall.

Lonchaea setifera de Meij.

De Meijere. Studien IV. Tijdschr. v. Entom. Bd. 53, p. 119.

Ceram, Februar.

SEPSINAE.

Piophila Fall.

Piophila ruficornis v. d. Wulp.

Waigeu, Dezember.

TRYPETINA.

Anomoea Walk.

Anomoea conjuncta n. sp.

Saonek, Januar, 1 Ex.

Stirne matt rotgelb, Fühler desgleichen, das $3^{\text {te }}$ Glied etwas grau; Fühlerborste kurz behaart. Untergesicht gelbweiss. Thorax graubraun,-weisslich bereift, bei binterer Ansicht mit 2 . braunen Längsstriemen. Brustseiten glänzend dunkelbraun. Schildchen von der Farbe des Thoraxrückens. Hinterleib schwarzbraun, mässig glänzend. Vorderbeine samt Hüften gelb, die Vorderschenkel an der Hinterseite dunkelbraun; an den übrigen Beinen sind Hüften und Schenkel dunkelbraun, die Schienen sind nur an der Wurzel bräunlich, im übrigen braungelb, die Tarsen ganz von letzterer Farbe. Flügel von der Wurzel bis über die hintere Querader hinaus grösstenteils schwarzbraun; der braune Flecken verlässt an der Mündung der $1^{\text {ten }}$ Längsader den Vorderrand und sendet weiterhin 2 bindenartige Fortsätze zu diesen hinauf, von welchen sich der äussere den Vorderrand entlang bis zur Flügelspitze umbiegt; in dem dadurch freigelassenen, glashellen Dreieck vor der Flügelspitze findet sich ein sich zum Hinterrand erstreckender Längsstrich; der Flügelhinterrand ist fast ganz glashell. Schwinger schwarzbraun.

Körper- und Flügellänge ca $3 \mathrm{~mm}$.

Acanthoneura Macq. ${ }^{1}$ ).

1. Acanthoneura Dunlopi v. d. Wulp., var. ceramensis nov. var.

Ceram, Februar.

Die Exemplare sind etwas kleiner und dunkler als die von Java. Der Thorax zeigt 2 dunkelbraune Längsstriemen; ferner einen dunklen Längsstrich an der Innenseite der Schulterbeule und hinter der Quernaht eine dunkle Seitenstrieme, welche sich hinten mit der benachbarten Mittelstrieme verbindet; das Schildchen ist schwarzbraun, nur an der Spitze gelblich; im Gegensatz zu den Java-Stücken trägt es am Rande nur 4 Borsten, statt 6, weil die 2

1) Auf die Abgrenzung der Gattungen Rioxa und Acanthoneura hoffe ich im 7 ten Teil meiner Studien über südostasiatische Dipteren zurückzukommen. 
übrigen, d. h. die $2^{\text {te }}$ und $5^{\text {te }}$; nur durch kurze Härchen vertreten sind. Auch das Abdomen ist grösstenteils schwarzbraun, nur an der Wurzel z. T. heller. Der Flügel ist namentlich an der Wurzel dunkler, die Bräunung setzt sich deutlich unter der 5ten Längsader bis zum Flügelrande fort. Die untere Spitze des weissen Fleckchens an der Spitze der 1 ten Längsader liegt der kleinen Querader mehr genähert, meistens kaum etwas hinter dieser.

Körper- und Flügellänge ca $5 \mathrm{~mm}$.

\section{Acanthoneura minuta n. sp.}

Saonek, Januar, 1 o', 1 Q.

Stirne mattgelb, die Periorbiten glänzend gelb; jederseits 4 Orbitalborsten; die oberste ist am kürzersten und schwächsten, die $2^{\text {te }}$ am stärksten, die 2 vorderen sind nach innen gerichtet und gleichstark. Fühlerwurzel schwarzbraun, 3'tẹs Glied gelblich weiss, eiförmig, den Mundrand nicht erreichend; Fühlerborste'schwarzbraun, oben langgefiedert, unten kürzer. Untergesicht, die kurzen Backen, Taster und Rüssel weissgelb. Hinterkopf weissgelb, oben mit 2 nach aussen umgebogenen braunen Strichen dicht neben einander.

Thorax gelb, vorn mit 2 länglichen braunen Fleckchen, an welche sich eine schmale hintere Begrenzung der Schulterbeulen anschliesst, hinter der Quernaht mit 2 in ihrer Mitte abgebrochenen dunklen Längslinien, deren hintere Hälfte etwas mehr seitwärts liegt als die vordere; am Seitenrande vor der Flügelwurzel 2 dunḳle Fleckchen; Schildchen weissgelb mit einem grossen, längsovalen, dunkelbraunen Flecken in der Mitte, sodass nur ein breiter Randsaum von der hellen Grundfarbe übrig bleibt; der Rand trägt 6 Borsten, von welchen jederseits die mittlere schwächer ist. Praesuturalborste vorhanden. Brustseiten gelbweiss, in der oberen Hälfte mit einer dunkelbraunen Längsstrieme. 2 Mesopleural-, 1 Sternopleuralborste vorhanden. Hinterleib gelb, in der hinteren Hälfte die Ringe namentlich am Hinterrande schwarzbraun. Bauchseite gelb; vor dem Hypopyg beobachtet man 2 stabförmige Gebilde neben einander, welche an der Spitze hinten je einen schwarzen Punkt tragen. Beine ganz gelb; Vorderschenkel unten mit starken, schwarzen Borsten. Flügel relativ schmal, die $1^{\text {te }}, 3^{\text {te }}$ und $5^{\text {te }}$ Längsader beborstet, die Längsadern auch in der distalen Hälfte gerade. Die kleine Querader liegt unter der Spitze der $1^{\text {ten }}$ Längsader, etwas jenseits der Mitte der Discoidalzelle; der Zipfel der Analzelle is relativ kurz, die abschliessende Querader rechtwinklig geknickt. Während die Wurzelhälfte des Flügels ganz glashell ist, ist die Spitzenhälfte von der Spitze des Vorderastes der $1^{\text {ten }}$ Längsader an dunkelbraun; die Trennungslinie läuft nach unten hin fast durch die Mitte der Discoidalzelle.

Körperlänge 4,5 mm.; Flügellänge $4 \mathrm{~mm}$.

Beim Weibchen ist der letzte Hinterleibsring stark verlängert und zum Anfangsteil der Legeröhre geworden: er schliesst sich dem vorigen Ringe breit an, ist stark abgeflacht und etwa $2 / 5$ so lang wie der ganze Hinterleib; die Farbe ist dieselbe wie diejenige der vorhergehenden Ringe, nämlich gelbbraun, mässig glänzend. Die Zellen in der Spitzenhälfte der Flügel zeigen je eine hellere Längslinie in ihrer Mitte; die $2^{\text {te }}$ Hinterrandzelle ist am Flügelrande breit glashell.

Körperlänge fast $5 \mathrm{~mm}$.; Flügellänge fast $4 \mathrm{~mm}$.

ORTALINAE.

Scholastes Löw.

Scholastes cinctus Guér.

Waigeu, 1 \%; (?) Ceram, 1 ㅇ.

Das Exemplar von Ceram zeichnet sich durch für diese Art besonders dunkle und z. T. auch breite Flügelbinden aus. Überdies sind die Hinterschienen an der Aussenseite schwarz. Vielleicht liegt hier eine besondere Art vor. 
Achias Fabr.

Waigeu, Januar, 1 o

Achias dacoides Walk.

Das Exemplar stimmt mit WALKER's Beschreibung; nur zeigen sich keine schwarzen Längsstriemen am Thorax. Die Hinterleibsspitze zieht ins Metallisch-schwarze. Am Ende der Discoidalzelle findet sich ein dunkler Wisch.

Die Körperlänge ist $9 \mathrm{~mm}$., die Flügellänge $8 \mathrm{~mm}$. (also von W ALKER zu gross angegeben).

Cleitamia Macq.

1. Cleitamia Catharinae n. sp. (Fig. 25).

Waigeu, Januar, Dezember.

Stirne matt schwarzbraun, Ocellendreieck und die kurzen Periorbiten stahlblau, der Vorderrand mattschwarz gesäumt. Fühler an der Wurzel gelbrot, das $3^{\text {te }}$ Glied matt bräunlich rot. Untergesicht mattgelb, in der oberen Halfte etwas dunkler. Praelabrum gelblich weiss. Backen bräunlich; Hinterkopf bläulich schwarz.

Thorax bläulich schwarz, fast matt, längs der Quernaht mit einer sammet-braunschwarzen Linie. Die Bestäubung des Thorax spärlich, braun. Brustseiten glänzend grünlich-schwarz. Hinterleib metallisch schwarz, ziemlich glänzend. Beine schwarz, Vorderhüften und alle Schenkel gelb, nur die Spitze letzterer verdunkelt. Flügel (Fig. 25) grösstenteils schwarz, glashell sind nur 3 dreieckige Fleckchen am Vorderrande, zwei Striche unter der Spitze und ein von der oberen Spitze der untersten derselben schief wurzelwärts zum Hinterrand verlaufender; auch der Hinterrand zum Teil schmal glashell gesäumt. Schwinger schwarz.

Körperlänge $\gamma \mathrm{mm}$; Flügellänge $\%, 5-8 \mathrm{~mm}$.

Beim $q$ ist das Untergesicht und das Praelabrum dunkelbraun, der obere Teil des Untergesichtes ist fast schwarz, unter der Fühlerwurzel jedoch weiss bereift; auch das $3^{\text {te }}$ Fühlerglied ist dunkelbraun.

In der Flügelfärbung ähnelt diese Art am meisten Cl. Osten-Sackeni Kert. (Termesz. Füz. XXI, 494 und Ann. Mus. Stor. nat. Genova XXXIX, 1898, p. 563, Taf. VII. Fig. 5). Die schwarze Farbe hat sich bei dieser Art nicht so weit ausgedehnt, sodass hier 3, an der oberen Spitze zusammenhängenđe, glashelle Binden, welche nach untèn divergieren, zu beobachten sind. Auch diese schöne Art möge Frau de Beaufort gewidmet sein.

2. Cleitamia liturata Ost. Sack.

Waigeu, Januar.

3. Cleitamia astrolabei Boisd.

Waigeu, Januar.

\section{Stenopterina Macq.}

1. Stenopterina aenea Wied.

Waigeu, Dezember.

2. Stenopterina geniculata v. d. W.

Waigeu, Dezember.

Das Exemplar stimmt mit den als geniculata bestimmten Stücken von Java überein, namentlich durch die gelbliche Randzelle.

3. Stenopterina unimaculata Kert.

Ceram, Februar, 1 ㅇ. 
Rivellia Rob. Desv.

Rivellia dimidiata de Meij.

De MeiJere. Studien II, Tijdschr. v. Entom. Bd. 51, p.:122.

Waigeu, Dezember; Saonek, Januar.

Pseudeuxesta Hendel.

Pseudeuxesta prima 0st. Sack.

Hendel. Genera Insectorum, fasc. 110, Ulidiinae, 1910, p. 30.

Ceram, Februar.

Adrama Walk.

Adráma selecta Walk.

Diese Art sieht Adr. determinata sehr ähnlich. Am Mundrande finden sich 2 schwarze Punkte, bisweilen sind diese jedoch kaum erkennbar. Bei Adr. determinata zeigt der Mundrand einen schwarzen Querflecken, der schwarze Flecken auf der Stirne ist grösser, auch am Hinterkopf beobachtet man ein schwarzes Fleckchen. Die erste dunkle Flügelbinde ist bei dieser Art schmäler und weniger vortretend als bei selecta.

\section{CHLOROPINAE.}

Chlorops Meig.

1. Chlorops nicobarensis Schin.

Saonek, Januar; Waigeu, Dezember.

2. Chlorops de-Beauforti n. sp.

Ceram, Februar.

Stirne matt rotgelb, kurz weisslich behaart, unbeborstet. Scheiteldreieck glänzend dunkelbraun, schmal dreieckig, hinten kaum mehr als $1 / 3$ der Stirnbreite einnehmend, mit geraden Rändern, allmählich verschmälert vorn fast den Vorderrand der Stirne erreichend. Fühler mattschwarz, das $3^{\text {te }}$ Glied gross, rund, die Borste nackt, dunkel. Untergesicht und Backen weissgelb, die Backen mässig breit. Taster und Rüssel gelb. Hinterkopf in der Mitte grau, an den Seiten gelb.

Thorax gelbrot, mit 3 breiten, nur durch gelbe Linien getrennten schwarzbraunen Längsstriemen, wenig glänzend, dicht kurz gelblich behaart. Brustseiten rot mit einigen schwarzen Fleckchen, u. a. einem grösseren unten auf den Sternopleuren. Schildchen braungelb, oben flach, kurz weisslich behaart, ohne Randborsten. Hinterleib grösstenteils schwarz, glänzend, am Seitenrande rötlich. Beine schwarzbraun, die Kniee gelb, die kurze Behaarung weisslich. Flügel fast gleichmässig gebräunt, der Hinterrandsteil von der Ausmündung der $4^{\text {ten }}$ Längsader an etwas heller; $3^{\text {te }}$ Längsader gerade. Schwinger weiss.

Körper- und Flügellänge $2.5 \mathrm{~mm}$.

Von Chl. paludosa de Meij. unterscheidet sich diese Art durch geringere Grösse, dunklere Beine, dunkle Fühlerwurzel u.s. w.

\section{Chloropsina Becker.}

Chloropsina leucochaeta n. sp.

Becker. Ann. Mus. Nat. Hung. IX. 1911, p. 51.

Ceram, Februar.

Stirne rotgelb, das sehr grosse Scheiteldreieck glänzend schwarz, den Vorderrand der Stirne fast erreichend, die Seitenränder etwas nach aussen gebogen. Fühler schwarz, das $3^{\text {te }}$ 
Glied gross, rund, die Borste weiss, durch Pubescenz etwas dick erscheinend. Untergesicht und die äusserst schmalen Backen rotgelb. Thoraxrücken glänzend schwarz, äusserst kurz schwarz behaart, unbeborstet, der Seitenrand gelbrot, auch die Brustseiten von dieser Farbe, mit 3 schwarzen Fleckchen. Schildchen rotgelb, Hinterrücken schwarz. Hinterleib conisch, spitz endend, metallisch schwarz, der 1 te Ring grösstenteils gelbrot. Beine rotgelb, die Hinterschenkel mit Ausnahme der Spitze schwarzbraun; an den Vorderbeinen die 3 letzten Tarsenglieder verdunkelt, an den hinteren nur das letzte. Flügel glashell. 2te Längsader ziemlich lang, gerade; der $2^{\text {te }}$ Abschnitt der Randader entschieden länger als der dritte. Kleine Querader vor der Mitte (auf $1 / 3$ ) der Discoidalzelle. Schwinger weiss.

Körperlänge 1,5 mm.; Flügellänge 1,25 mm.

Von den beiden von Beck in in diese Gattung gestellten Arten, bzw. von der Gattungsdiagnose weicht die vorliegende Art durch das gelbe Schildchen und die längere $2^{\text {te }}$ Längsader ab. Zu Formosina Beck. kann sie wegen der grösseren Augen; des gewölbten Schildchens und der Stellung der kleinen Querader noch weniger gut gestellt werden.

\section{Oscinella Becker.}

1. Oscinella maculata Becker.

Becker. Ann. Mus. Nation. Hungar. IX. 1911, p. 155.

Saonek, Dezember; Ceram, Februar.

2. Oscinella ornatifrons de Meij.

De Meidere. Studien II. Tijdschr. v..Entom. Bd. 51, p. 174 (Oscinis ornatifrons).

Waigeu, Januar.

Das Exemplar ist etwas grösser als die Type, die Flügellänge beträgt 3,5 mm.; die Hintermetatarsen sind gelb.

$$
\begin{gathered}
\text { Hippelates Löw. } \\
\text { Hippelates nigricornis Thoms., var. flavus Thoms. }
\end{gathered}
$$

Becker. Ann. Mus. Nat. Hungar. 1X, 1911, p. 103.

Saonek, Januar.

\section{EPHYDRINAE.}

Paralimna Löw.

Paralimna hirticornis n. sp.

Saonek, Januar, 1 Ex.

Stirne schwarz, gelbgrau bestäubt, vorn glänzend, Fühler schwarzbraun, das 2te Glied oben mit grossem, weissem Punkte, das $3^{\text {te }}$ Glied namentlich am Oberrande auffällig lang behaart. Fühlerborste oben mit 8 Kammstrahlen. Backen und Untergesicht matt bräunlich weiss; letzteres jederseits mit 3 Börstchen, von welchen das obere bei weitem am stärksten ist.

Thorax schwarzbraun; mässig glänzend, dünn heller braun bereift, in der Mittellinie 2 Reihen sehr kleiner, wenig auffalliger gelber Fleckchen; das grosse Notopleuraldreieck und die Brustseiten grauweiss. Schildehen schwarzbraun. Hinterleibsringe vorn matt schwarzbraun, in der hinteren Hälfte matt weisslich, an den hinteren Segmenten diese Binden durch eine braune Rückenlinie geteilt, neben welcher sie sich weit nach vorn erstrecken; Seitenrand der Tergite ganz weiss.

Beine schwarzgrau, die Schienen mit weisslichem Schimmer, die Metatarsen gelb. Flügel sehr schwach gebräunt, das Geäder braungelb.

Körper- und Flügellänge 2,75 $\mathrm{mm}$. 


\section{Discomyza Meig. \\ Discomyza maculipennis Wied.}

Dr MeIJERE. Studien II, p. 166.

Saonek, Dezember.

Stratiothyrea n.g. (Fig. 26).

Stirn (Fig. 26) sanft gewölbt, ganz glänzend. Fühler kurz, das dritte Glied von ovaler Gestalt; die Borste nur oben gefiedert. $2^{\text {tes }}$ Glied mit einem nach vorn gerichteten Börstchen. Augen nackt. Untergesicht unten buckelig gewölbt, jederseits mit einem kurzen Börstchen. Praelabrum vortretend. Thorax kurz und hoch, gewölbt; Schildchen nicht besonders gross, aber etwas aufgerichtet und hinten 2 kurze Dornen tragend, auf welchen je eine Borste eingepflanzt ist. Hinterleib kurz und breit, etwas länger und breiter als der Thorax, ebenfalls gewölbt, der $5^{\text {te }}$ Ring kurz; Vorderschenkel und -schienen stark verdickt, namentlich die Schenkel; an der Aussenseite sind diese, nahe der Wurzel, in einen stumpfen Zahn verbreitert und werden von dieser Stelle nach der Spitze hin allmählich dünner. Flügel relativ schmal, die $2^{\text {te }}$ Längsader lang, die $3^{\text {te }}$ und $4^{\text {te }}$ parallel; die Queradern einander genähert; die hintere Querader noch etwas vor. der Flügelmitte; die kleine steht unter der Ausmündung der ersten Lăngsader. Die Randader endet an der Spitze der $4^{\text {ten }}$ Längsader. Die Beborstung kann ich nicht genau angeben, weil das Exemplar in dieser Hinsicht nicht vollständig ist. Am Thorax beobachte ich nur ganz hinten eine Borste.

Die Gattung ist mit Athyroglossa verwandt, sie unterscheidet sich durch die verdickten Vorderschenkel, das eigentümliche Schildchen, die mehr genäherten Queradern u.s.w.

\section{Saonek, Dezember, 1 Ex.}

Stratiothyrea femorata n. sp. (Fig. 26).

V́on glänzend schwarzer Farbe, auch die Stirne ganz glänzend schwarz. Fühler matt schwarzbraun, die untere Hälfte des kurzovalen $3^{\text {ten }}$ Gliedes gelb. Untergesicht stark gewölbt, höckerartig, wie poliert, auch das Praelabrum glänzend schwarz; Rüssel rötlich.

Thorax glänzend schwarz, kurz schwarz behaart. Schildchen etwas aufgerichtet, gewölbt, am Ende mit 2 kurzen Dörnchen, welche je eine schwarze Borste tragen. Hinterleib glänzend schwarz. Beine desgleichen, nur die Tarsen bis auf das schwarze letzte Glied weiss. Flügel glashell.

Körperlänge fast $2 \mathrm{~mm}$; Flügellänge $1,5 \mathrm{~mm}$.

Hemicyclops gen. n. (Fig. 2\%).

Stirn (Fig. 2\%) ganz flach, in gewisser Richtung erscheint ein vom Augenrande überall gleichbreit getrenntes, vorn sich bis zum vorderen Stirnrand erstreckendes Dreieck von etwas hellerer Farbe, welches vor den Ocellen 2 Börstchen trägt; jederseits 2 Ocellare vorhanden. Augen halbkreisförmig, mit geradem Innenrande, nackt. Fühler kurz, das $3^{\text {te }}$ Glied rund, die Borste kurz, oben mit einigen Kammstrahlen. Das $2^{\text {te }}$ Glied oben vorn mit einem nach vorn gekrümmiten Börstchen, hinten mit einer längeren, aufgegerichteten Borste. Untergesicht lang, unter den Fühlern ausgehöhlt, in der Mitte vorspringend und dort mit einem glänzend schwarzen Punkt; jederseits 3 Borsten vorhanden: Backen sehr breit, nackt. Prälabrum nicht vorragend. Mundöffnung relativ klein und schmal, am Rande nicht beborstet; Saugflächen des Rüssels ziemlich lang. Hinterkopf wenig ausgehöhlt.

Thorax dem Kopfe eng anliegend, kurz und breit, wenig gewölbt, sehr kurz behaart, oben unbeborstet, nur an den Seiten und am Hinterrand ein Paar Börstchen bemerkbar, auch die Meso- und Sternopleuralborste kurz. Schildchen breit, ziemlich flach, am Rande mit 4 schwachen Borsten nebst einigen Härchen; Hinterleib kurz und flach, so lang wie der Thorax, kurzbehaart; 5-ringlig. Beine mässig lang, stark, die Vorderschenkel etwas verdickt. Mittelschienen an der Spitze mit einer längeren Borste, die Aussenseite gleichmässig kurz beborstet. Flügel relativ breit, die $1^{\text {te }}$ Längsader kurz, der 1te Abschnitt der Randader kurz beborstet; keine längere Borste an der Ausmündung der 1 $1^{\text {ten }}$ Längsader; 2te Längsader lang; gerade, 
$3^{\text {te }}$ und $4^{\text {te }}$ etwas convergierend; hintere Querader etwas nach aussen gebogen, etwa so lang wie der letze Abschnitt der $5^{\text {ten }}$ Längsader. Discoidal- und mittlere Basalzelle verschmolzen; kleine Querader etwas vor der Mündung der $1^{\text {ten }}$ Längsader; der letzte Abschnitt der $4^{\text {ten }}$ Längsader etwas länger als der vorletzte; Randader bis zur Spitze der 4 ten Längsader fortgesetzt.

Die Gattung ist mit Hecamede nahe verwandt; sie unterscheidet sich durch die flachere und längere Stirne, das längere Untergesicht, die seitlich stark komprimierte Mundöffnung, durch das Fehlen der überzähligen Borstenreihen auf der Stirn, durch die nicht unbeborsteten Backen. Im Kopfprofil zeigt sich auch Ähnlichkeit mit Elephantinosoma Becker ${ }^{1}$ ), welche aber wegen der grossen Mundöffnung und das unbedornte $2^{\text {te }}$ Fühlerglied zu den Ephydrinen gehört.

$$
\text { Hemicyclops planifrons n. sp. (Fig. 27). }
$$

Waigeu, Dezember, 1 Ex.

Stirne matt graugelb, das Dreieck reiner gelb. Wurzelglieder der Fühler rotbraun, glänzend, das $3^{\text {te }}$ Glied schwarz, die schwarze Borste oben mit 4 Kammstrahlen. Untergesicht und Backen gelblich, weisslich bestäubt. Rüssel braun. Thorax graugelb bestäubt. Brustseiten weissgrau; vorn unten mit einem grossen, glänzend schwarzen Fleck. Hinterleib ebenfalls matt graugelb. Hüften und Schenkel grauweiss bestäubt. Schienen und Tarsen, beide mit Ausnahme der Spitze, gelb, ebenfalls mit weisslicher Bestäubung. Flügel etwas weisslich. Schwinger weissgelb.

Körperlänge $2 \mathrm{~mm}$; Flügellänge $1,5 \mathrm{~mm}$.

Hydrellia Rob. Desv.

Ceram, Februar, 1 Ex.

$$
\text { Hydrellia ceramensis n. sp. }
$$

Stirne matt grünlich grau, Lunula weisslich; Wurzelglieder der Fühler -schwarz, das $3^{\text {te }}$ Glied kurz, dreieckig braungelb, die Spitze und die Aussenseite dunkler; Fühlerborste mit 9 Kammstrahlen. Untergesicht ledergelb, jederseits mit 5 Börstchen. Backen sehr schmal. Taster gelb. Thorax matt grünlich-grau, der Seitenrand und die Brustseiten heller, weisslichgrau, Hinterleib oben grünlich bronzefarbig, die Unterseite matt weissgrau. Vorderhüften gelb, hintere Hüften grau, Schenkel alle grau, weisslich bestäubt, nur die Spitze schmal gelb; Trochanteren alle gelb, desgleichen alle Schienen und Tarsen, an letzteren nur das Endglied dụnkel. Flügel glashell, die $2^{\text {te }}$ Längsader gerade, der $3^{\text {te }}$ Abschnitt der Randader 1,\% mal so lang wie der $2^{\text {te }}, 3^{\text {te }}$ und $4^{\text {te }}$ Längsader parallel. Schwinger gelb.

Körper- und Flügellänge $1,5 \mathrm{~mm}$.

\section{DROSOPHILINAE.}

Drosophila Fall.

Drosophila pumilio de Meij.

De Meisere. Studien II. Tijdschr. v. Entom. LI, p. 153.

Saonek, Dezember.

$$
\text { Camilla Hal. }
$$

Camilla javána de Meij.

De Meidere. Studien VI. Tijdschr. v. Entom. LIV, p. 422.

West-Ceram, van Dedem.

\section{AGROMYZINAE.}

Agromyza Fall.

Agromyza erythrinae de Meij.

De Meijere. Studien IV. Tijdsehr, v. Ent. LIII, p. 160.

Ceram, Februar.

1) Becrer, Tr. Aegyptische Dipteren II. Mitt. Zool. Mus. Berlin II. 1903, p. 179. 


\section{TAFELERḰL A RUNG.}

1. Sciara turrita n. sp. Kopf.

2. $\cdots, \quad \cdots$ Flügel.

3. Leia nigra n. sp. Flügel.

4. Dicranomyia de-Beauforti n. sp. Flügel.

5. Mongoma obscura n. sp. Flügel.

6. Chrysopilus opalizans $\mathrm{n}$. sp. F'ügel.

\%. Leptogaster rufthorax n. sp. Flügel.

8. Astylopogon Catharinae n. sp. Fühler.

$9 . " \quad "$ Hinterbein.

10. " " " " " Flügel.

11. Ommatius bisetus n. sp. Männliches Copulationsorgan.

12. Syndyas aterrima n. sp. $\sigma^{7}$. Flügel.

13. Psilopus pectoralis n. sp. $\sigma^{7}$. Hypopyg.

14. '." obscuripennis : n. sp. $\sigma^{r}$. Flügel.

15. " \# \# \# Hypopyg.

16. " " ceramensis n. sp. " $\sigma^{7}$. Flügel.

17. " " \# Hypopyg.

18. " albicinctus n. sp. ơ. Hypopyg.

19. " saonekensis n. sp. $\sigma^{\top}$. Flügel.

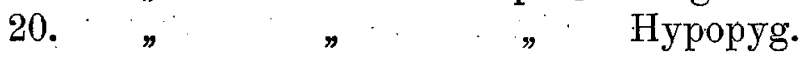

21. " sericeus n. sp. " $\sigma^{7}$. Flügel.

22. $;$ ", Hypopyg.

23. $" ~ "$ waigeensis n. sp. $\sigma^{7}$. Flügel.

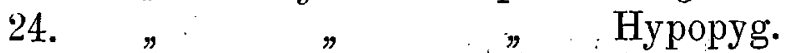

25. Cleitamia Catharinae n. sp. Flügel.

26. Strathiothyrea n. g. femorata n. sp. Kopf.

2\%. Hemicyclus n. g. planifrons n. sp. Kopf. 
Bijdragen tot de Dierkunde.

J. C. H, DE Meijere, Dipteren Taf. I

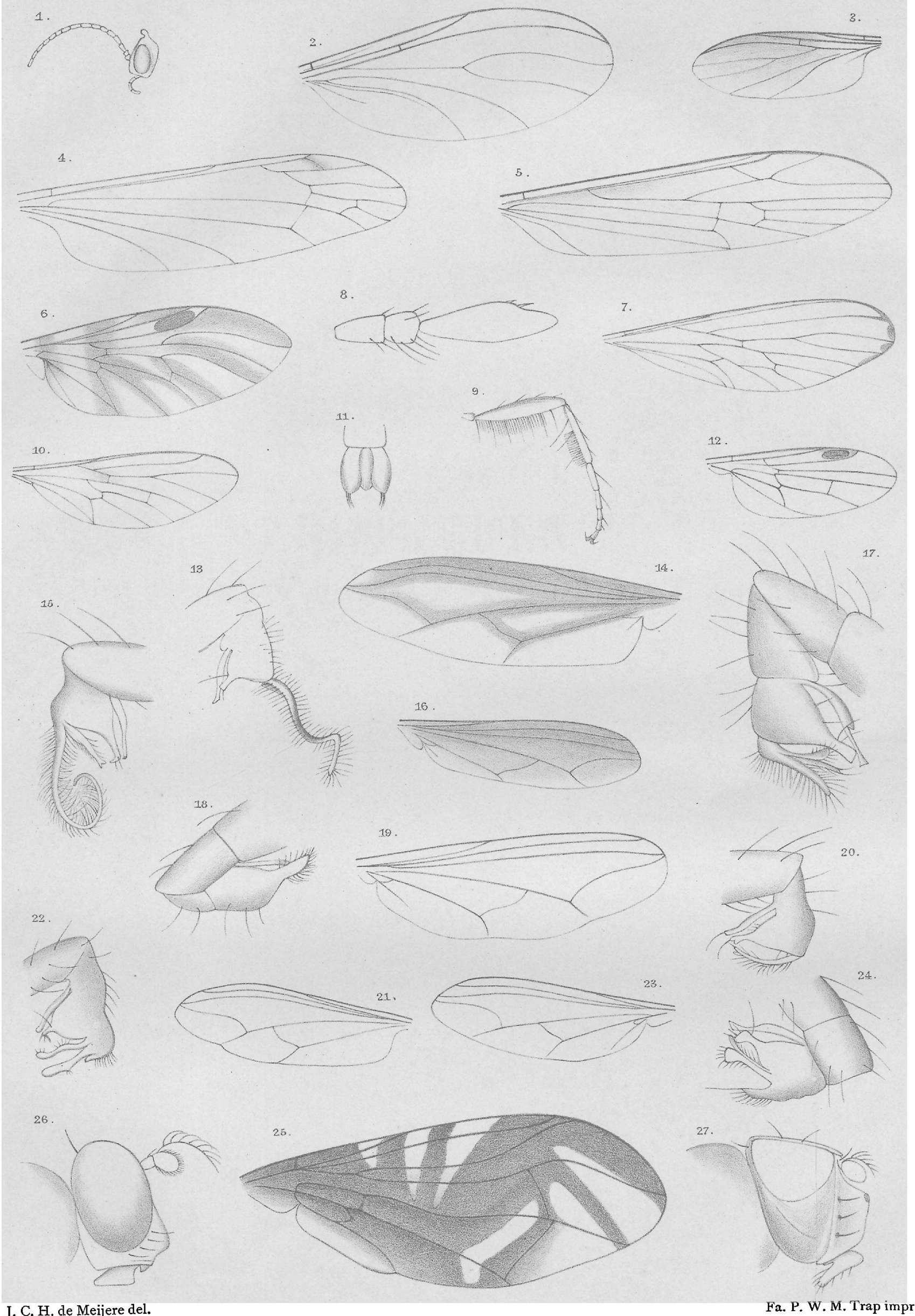

